\title{
Synthesis and characterization of nitrogen-doped titania nanomaterials of homogeneous particle size
}

\author{
Nurul Diyana Zainal ${ }^{1}$, Hadi Nur ${ }^{2}$, Siew Ling Lee ${ }^{2^{*}}$ \\ ${ }^{1}$ Department of Chemistry, Faculty of Science, Universiti Teknologi Malaysia, 81310 Johor Bahru, Johor, Malaysia \\ ${ }^{2}$ Center for Sustainable Nanomaterials, Ibnu Sina Institute for Scientific and Industrial Research, Universiti Teknologi Malaysia, 81310 Johor Bahru, \\ Johor, Malaysia \\ "Corresponding Author: sllee@ibnusina.utm.my
}

\section{Article history :}

Received 5 November 2015

Accepted 15 November 2015

\section{GRAPHICAL ABSTRACT}

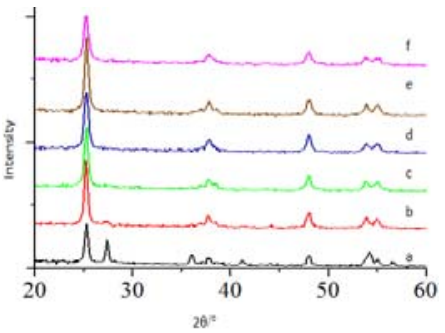

\section{ABSTRACT}

Modification of sol-gel method was used to synthesize homogeneous particle size nitrogen-doped titania $\left(\mathrm{N}-\mathrm{TiO}_{2}\right)$ nanomaterials using tetraethyl ammonium hydroxide (TEAOH) as $\mathrm{N}$ source. XRD analysis showed that these $\mathrm{N}-\mathrm{TiO}_{2}(1-5 \% \mathrm{~N}$ concentration) crystallined in anatase structure. The crystallinity of the samples decreased with increasing of $\mathrm{N}$ content. The calculation using Scherrer equation showed that the particle size of the synthesized $\mathrm{N}-\mathrm{TiO}_{2}$ ranged $15.02-26.85 \mathrm{~nm}$, strongly suggesting attainment of nanomaterials. DR UV-Vis results indicated that the band gap energy of $5 \% \mathrm{~N}$ doped $\mathrm{TiO}_{2}$ was only $2.58 \mathrm{eV}$, implying the sample could be a potential photocatalyst under visible light irradiation Homogeneous particle size of the synthesized nanomaterials was evidenced through FESEM images. Meanwhile, the EDX analysis confirmed the homogenous distribution of elements $\mathrm{Ti}, \mathrm{N}$ and $\mathrm{O}$ in $5 \% \mathrm{~N}$ doped titania sample.

Keywords: titania, nitrogen, doped, nanomaterials, homogeneous

(C) 2015 Penerbit UTM Press. All rights reserved http://dx.doi.org/10.11113/mjfas.v11n3.378

\section{INTRODUCTION}

Nanomaterial titanium dioxide $\left(\mathrm{TiO}_{2}\right)$ has been extensively used as a pigment [1] and in sunscreen [2], paints [3], toothpaste [4] etc. $\mathrm{TiO}_{2}$ nanomaterial has been receiving much attention for its good photocatalytic [5] and hydrophilic properties [6]. These works on application and fundamental aspects of $\mathrm{TiO}_{2}$ are mainly related to the selfcleaning, chemical energy generation, and photovoltaic devices.

Metal doping on $\mathrm{TiO}_{2}$ [7] has been an important approach in band gap engineering to change the optical response of semiconductor photocatalysts. Metal doping induces a bathochromic shift (a decrease of the band gap or introduction of intra-band gap states), to increase the absorption of visible light. Doping may lead to photocatalytic systems that exhibit enhanced efficiency [8] which is desirable to maintain the integrity of the crystal structure of the photocatalyst while changing its electronic structure by doping. It is easier to replace $\mathrm{Ti}^{4+}$ in $\mathrm{TiO}_{2}$ with a cation than to substitute $\mathrm{O}^{2-}$ with another anion because of the difference in the charge states and ionic radii.

Many techniques have been examined to achieve this purpose, including the doping of $\mathrm{TiO}_{2}$ with transition metals [9], but these doped materials suffer from thermal instability and an increased number of recombination centres. Usage of transition metal has limited the application of textile and waste water related industries. Doping with anion atoms such as nitrogen seems to be more successful $[5,10]$. The introduction of substitutional $\mathrm{N}$ atoms into the $\mathrm{TiO}_{2}$ matrix improves optical absorption in the visible region, and leads to corresponding photochemical activity.

In this work, a series of nanostructured nitrogen doped titania were synthesized via sol-gel method. The properties and photocatalytic activity of the samples were presented.

\section{EXPERIMENTS}

\subsection{Nanomaterials Preparation}

The sol-gel procedure used in this study to synthesis $\mathrm{TiO}_{2}$ consists of 1:2:100 ratio of titanium tetraisopropoxide (TTIP), acetylacetone (AcAc) and ethanol, respectively. The sol-gel procedure used for $\mathrm{N}-\mathrm{TiO}_{2}$ preparation consists of same ratio with $0.06,0.13,0.19,0.26$ and $0.32 \mathrm{~cm}^{3}$ ratio of tetraethyl ammonium hydroxide (TEAOH) as source of nitrogen. TTIP was added dropwise into AcAc and was stirred with solvent ethanol at room temperature. The systems were stirred during the addition and then for an additional $60 \mathrm{~min}$, then TEAOH was added to the solution 
under vigorous stirring for $60 \mathrm{~min}$. The mixture was stirred in oil bath at $80^{\circ} \mathrm{C}$ until gelation was formed. The gelation was dried at $110{ }^{\circ} \mathrm{C}$ overnight, resulting formation of dry gels. The resulting dry gels were calcined at $500^{\circ} \mathrm{C}$ for $5 \mathrm{~h}$. Accordingly, nitrogen-doped titania containing 0.06, 0.13, $0.19,0.26$ and $0.32 \mathrm{~cm}^{3}$ ratio of TEAOH and pure titania were labeled as $1 \mathrm{~N}-\mathrm{TiO}_{2}, 2 \mathrm{~N}-\mathrm{TiO}_{2}, 3 \mathrm{~N}-\mathrm{TiO}_{2}, 4 \mathrm{~N}-\mathrm{TiO}_{2}, 5 \mathrm{~N}-$ $\mathrm{TiO}_{2}$ and $\mathrm{TiO}_{2}$, respectively.

\subsection{Characterization of nanomaterials}

The prepared nanomaterials were characterized via techniques of X-ray diffraction (XRD), diffuse reflectance UV-Vis (DR UV-VIS), field emission scanning electron microscopy (FESEM) and energy dispersive X-ray spectroscopy (EDX).

\section{RESULTS AND DISCUSSION}

\subsection{Synthesis of $\mathrm{TiO}_{2}$ and $\mathrm{N}-\mathrm{TiO}_{2}$ Nanomaterials}

TTIP was used as precursor and TEAOH was used as nitrogen dopant source. Acetyl acetone (AcAc) acted as chelating agent to control hydrolysis of titania precursor (TTIP) and precipitation of titania by forming chelate bond with $\mathrm{TiO}_{2}(a q)$. Figure 1 shows DR UV-Vis spectra of $\mathrm{TiO}_{2}$ and $\mathrm{N}$ dopedTiO ${ }_{2}$. The absorbance showed to be below 360 $\mathrm{nm}$. The calculated band gap energy of the synthesized $\mathrm{TiO}_{2}, 4 \mathrm{~N}-\mathrm{TiO}_{2}$ and $5 \mathrm{~N}-\mathrm{TiO}_{2}$ nanomaterials are $2.93,2.82$ and $2.58 \mathrm{eV}$, respectively. The synthesized $\mathrm{TiO}_{2}$ nanomaterials band gap energy is larger than the value of $2.58 \mathrm{eV}$ for the $5 \mathrm{~N}-\mathrm{TiO}_{2}$ nanomaterials. The narrower band gap is due to excitation of an electron from valence band to conduction band in $\mathrm{N}-\mathrm{TiO}_{2}$ and thus increasing its photocatalytic activity $[5,9]$.



Fig. 1 DRUV-Vis spectra of (a) $\mathrm{TiO}_{2}$, (b) $4 \mathrm{~N}-\mathrm{TiO}_{2}$ and (c) $5 \mathrm{~N}-$ $\mathrm{TiO}_{2}$

$\mathrm{XRD}$ was used to investigate the changes of phase structure of the pure $\mathrm{TiO}_{2}$ and nitrogen doped $\mathrm{TiO}_{2}$ after heat treatment at different mol concentration of nitrogen. Figure 2 shows the effect of nitrogen doping on the phase structure of pure titania. The XRD patterns of all samples contained diffraction peaks that appeared at 25.3, 37.7, $48.0,53.8$ and $54.9^{\circ}$, which were corresponded with typical pattern of anatase-type $\mathrm{TiO}_{2}$. There is a small peak at $27.4^{\circ}$ correspond to rutile phase was detected in $\mathrm{TiO}_{2}$ sample only. Apparently, introduction of nitrogen has hindered the formation of rutile phase, thus only anatase phase existed in these nitrogen doped $\mathrm{TiO}_{2}$ materials. Besides, the increase of $\mathrm{N}$ amount has reduced slightly the crystallinity of the materials. The width of the intense peak at $2 \theta=25.3^{\circ}$ was used to determine the crystallite size of the materials. As listed in Table 1, the crystallite size of $\mathrm{TiO}_{2}$ and $\mathrm{N}$ doped $\mathrm{TiO}_{2}$ ranged $15.02-26.85 \mathrm{~nm}$. The crystallite size of the materials was inversely proportional to the $\mathrm{N}$ content in the materials.

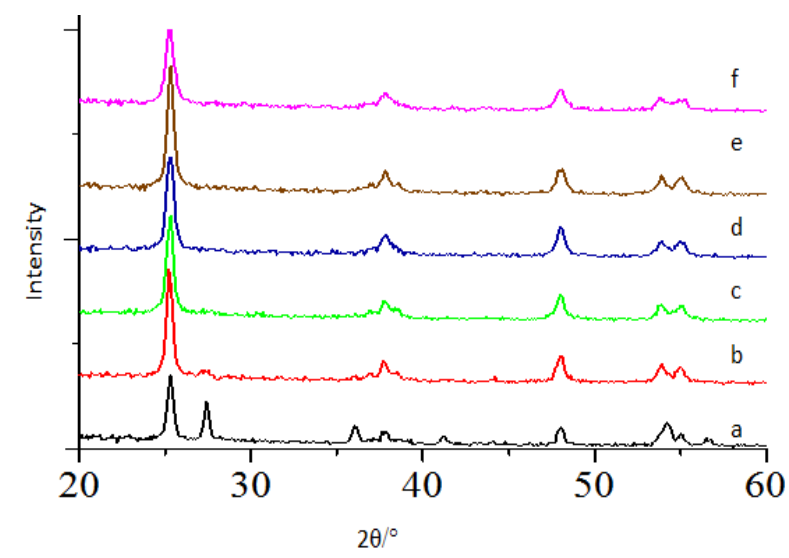

Fig. 2 XRD patterns of (a) $\mathrm{TiO}_{2}$, (b) $1 \mathrm{~N}-\mathrm{TiO}_{2}$ (c) $2 \mathrm{~N}-\mathrm{TiO}_{2}$, (d) $3 \mathrm{~N}-\mathrm{TiO}_{2}$ (e) $4 \mathrm{~N}-\mathrm{TiO}_{2}$, and (f) $5 \mathrm{~N}-\mathrm{TiO}_{2}$

Table 1 Crystallite size of $\mathrm{TiO}_{2}$ and nitrogen doped $\mathrm{TiO}$ calculated using Scherrer equation

\begin{tabular}{lc}
\hline Sample & Crystallite size(nm) \\
\hline $\mathrm{TiO}_{2}$ & 20.25 \\
$1 \mathrm{~N}-\mathrm{TiO}_{2}$ & 26.85 \\
$2 \mathrm{~N}-\mathrm{TiO}_{2}$ & 20.33 \\
$3 \mathrm{~N}-\mathrm{TiO}_{2}$ & 16.20 \\
$4 \mathrm{~N}-\mathrm{TiO}_{2}$ & 15.95 \\
$5 \mathrm{~N}-\mathrm{TiO}_{2}$ & 15.02 \\
\hline
\end{tabular}

\subsection{Homogeneity of Nanomaterials}

Morphology and the dispersion of particles were determined by using FESEM and energy dispersive X-ray analysis (EDX), respectively. Elemental composition analysis was carried out using with EDX. Figure 3 depicts the FESEM images for $\mathrm{TiO}_{2}$ and $5 \mathrm{~N}-\mathrm{TiO}_{2}$. Barbe et al. gave evidence that hindering the aggregation of anatase particles would suppress the formation of rutile [12]. Figure 3(a) shows that $\mathrm{TiO}_{2}$ has smooth surface, which most probably indicated aggregation of $\mathrm{TiO}_{2}$, whereas $3(\mathrm{~b})$ has rough surface, implied dispersion of nitrogen onto the 
surface of titania. The images revealed that the sample consists of agglomerates of primary particles with the crystallite size ranging from about $15-30 \mathrm{~nm}$ which is in good agreement with the crystallite size calculated from XRD pattern. Figure 3(b) shows the homogeneous particle size in $5 \mathrm{~N}-\mathrm{TiO}_{2}$. Elemental mapping via EDX analysis was carried out to examine the dispersion of nitrogen in the sample. From the Figure 4, the EDX mapping image denoted that the doped nitrogen molecules were homogeneously dispersed at $\mathrm{TiO}_{2}$ surface.
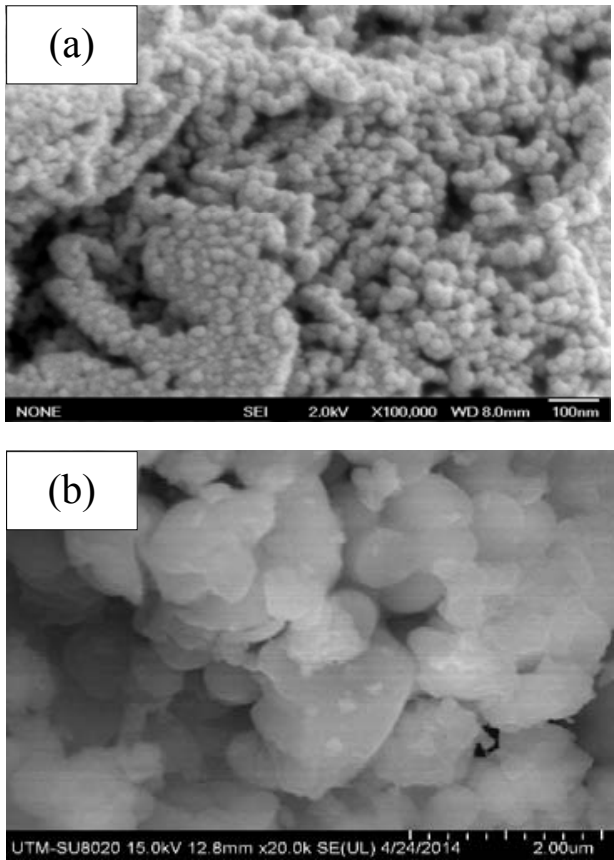

Fig. 3 FESEM images of (a) $\mathrm{TiO}_{2}$ and (b) $5 \mathrm{~N}-\mathrm{TiO}_{2}$
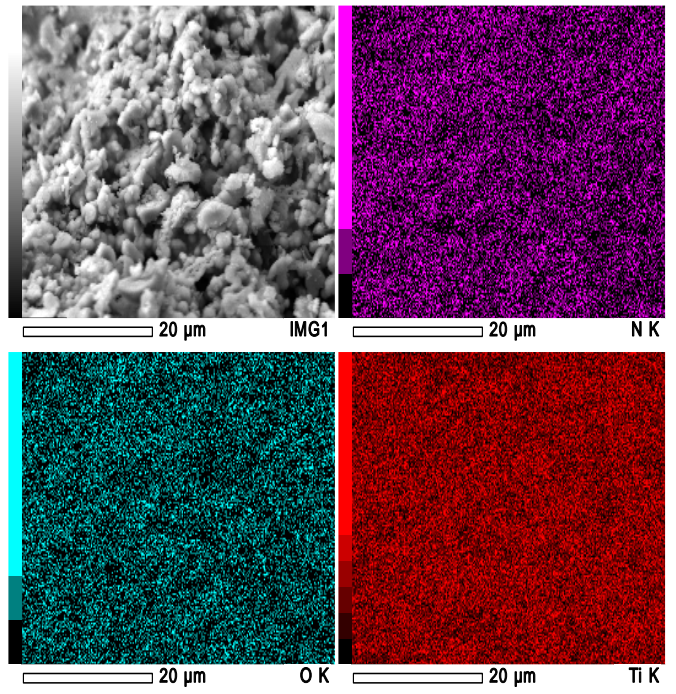

Fig. 4 EDX Mapping of $5 \mathrm{~N}-\mathrm{TiO}_{2}$

\section{CONCLUSION}

The synthesis of homogeneous nitrogen doped titania nanomaterials were successfully obtained using modified sol-gel method. The crystallinity of the samples decreased with increasing of $\mathrm{N}$ content. Homogeneous particle size of the synthesized nanomaterials was evidenced through FESEM images. The EDX analysis confirmed the homogenous distribution of elements Ti, N and $\mathrm{O}$ in $5 \% \mathrm{~N}$ doped titania sample.

\section{ACKNOWLEDGEMENTS}

This work was supported by the Research University Grant (Q.J130000.2526.10H54) from the Ministry of Higher education, Malaysia and Universiti Teknologi Malaysia (UTM). The authors also thank the Center for Sustainable Nanomaterials, Ibnu Sina Institute for Scientific and Industrial Research, UTM for the research facilities.

\section{REFERENCES}

[1] P.W. Lee, S.T. Ong, Y.T. Hung, S.L. Lee, Asian. J. Chem. 25 (2013) 755 .

[2] R. Wang, K. Hashimoto, A. Fujishima, Nature 388 (1997) 431.

[3] S.M. Gupta, M. Tripathi, Chinese Sci. Bull. 56 (2011) 1639.

[4] N.H.M Ran, L. Yuliati, S.L. Lee, T.M.I. Mahlia, H. Nur, J. Coll. Interf. Sci. 394 (2013) 490.

[5] H. Irie, Y. Watanabe, K. Hashimoto, J Phys. Chem B. 107 (2003) 5483.

[6] J.M. Ekhsan, S.L. Lee, H. Nur, Appl. Catal. A: Gen. 471 (2014) 142.

[7] N. Attan, H. Nur, J. Efendi, H. O. Lintang, S. L. Lee, I. Sumpono. Chem. Lett. 41 (2012) 1468.

[8] S.L. Lee, H. Nur, P.W. Koh, J.M. Ekhsan, S.C. Wei, Int. J. Appl. Phys. Math. 1 (2011) 43

[9] A.C. Lee, R.H. Lin, C.Y. Yang, M.H. Lin, W.Y. Wang, Mater. Chem. Phys. 109 (2008) 275.

[10] B. Xia, H. Huang, Y. Xie, Mater. Sci. Eng. 57 (1999) 150

[11] T. Morikawa, R. Asahi, T. Ohwaki, K. Aoki, K. Suzuki, Y. Taga, R \& D Review of Toyota CDRL. 40 (2005) 46.

[12] C.J. Barbe, F. Arendse, P. Comte, M. Jirousek, F. Lenzmann, V. Shklover, M. Gratzel, J. Am. Ceram. Soc. 80 (1997) 3157. 